\title{
25. LATE MIOCENE MAGNETIC STRATIGRAPHY AT DEEP SEA DRILLING PROJECT HOLE 521A ${ }^{1}$
}

\author{
Friedrich Heller and William Lowrie, Institut für Geophysik, Eidgenössische Technische Hochschule Zürich, \\ CH-8093 Zürich, Switzerland \\ and \\ James E. T. Channell, Lamont-Doherty Geological Observatory, Palisades, New York
}

\begin{abstract}
The magnetic properties of fresh, upper Miocene sediment samples from DSDP Hole 521A are dominated by magnetite. Alternating magnetic field (AF) demagnetization reveals a stable remanent magnetization component but is unable to reduce it to zero. Thermal demagnetization of samples that have been dehydrated isolates a well-defined stable component, but the procedure becomes ineffective at high temperature, probably because of alteration of the magnetic mineralogy. A combination of AF and thermal cleaning was employed to define the magnetic stratigraphy for this hole. Correlation of the magnetic polarity zonation with the magnetic time scale derived from oceanic magnetic anomalies was aided by nannofossil zonations. Normal polarity of the basal sediments agrees with the site position on Anomaly 5C. Tentative identifications of magnetozones that correspond to Anomalies 5, 5A, and 5B can also be made; above this level the magnetic stratigraphy does not have sufficient character to permit correlations. The sedimentation rate calculated from the magnetic zonation is very low, averaging $2.0 \mathrm{~m} / \mathrm{m}$.y.; close to the bottom of the hole the rate is about $7 \mathrm{~m} / \mathrm{m}$.y. The magnetozone identified with Anomaly 5 is found in association with nannofossil zones NN9/NN10.
\end{abstract}

\section{INTRODUCTION}

Magnetic stratigraphy studies in continental exposures of pelagic limestones have confirmed the geomagnetic polarity sequence derived from oceanic magnetic anomalies for the Late Cretaceous and Paleogene (Lowrie and Alvarez, 1977; Lowrie et al., 1982; Napoleone et al., 1983). A new magnetic polarity time scale for this time (Lowrie and Alvarez, 1981) was prepared by a threestage process: (1) the positions of 12 key biostratigraphic stage boundaries in these sections were correlated with the reversal sequence, (2) the best available age estimates were associated with these calibration levels, and (3) the ages of intervening reversal boundaries were dated by linear interpolation between calibration levels. When this new time scale was used, the age of the bottom sediment in Paleogene and Late Cretaceous DSDP sites was found to agree well with the age associated with the anomaly on which the hole was drilled (Lowrie and Alvarez, 1981, fig. 4). This agreement indicates that the magnetic time scale and the biostratigraphic ages are well correlated for this period of time. In the Neogene, however, there are large discrepancies, mainly because direct magnetostratigraphic correlations of the oceanic magnetic polarity record have not yet been carried out for the entire period.

The correlation of the Neogene magnetic and biostratigraphic records was attempted by Ryan et al. (1974). The method used to achieve the correlation was unavoidably circuitous and indirect because of the ab-

\footnotetext{
${ }^{1}$ Hsü, K. J., LaBrecque, J. L., et al., Init. Repts. DSDP, 73: Washington (U.S. Govt. Printing Office). This chapter represents Institut für Geophysik, ETH-Zürich, Contribution No. 379.
}

sence of suitable paleomagnetic stratigraphy results. Magnetic zonation of deep-sea sediment cores gave a good match with the polarity sequence in radiometrically dated lavas and extended the correlation with the oceanic reversal sequence into the late Pliocene (Opdyke, 1972), but the application of this method to older sediments depended on finding surface hiatuses on the ocean bottom and piecing together the polarity sequences from overlapping core segments. Theyer and Hammond (1974) used this method to obtain coverage for most of the Neogene. Continental magnetic stratigraphy studies in Pakistan have recently permitted the correlation of early Pliocene and late Miocene polarity zonations with the oceanic record (Tauxe and Opdyke, in press).

Many early studies of the magnetic stratigraphy of sediments drilled from DSDP sites were plagued by magnetic disturbance and incomplete core recovery. The first of these problems appears to have been overcome with the introduction of the hydraulic piston corer. The second problem has been partially solved by using this device, but incomplete recovery continues to leave hiatuses in the DSDP magnetic record and reduces the reliability of correlations with the oceanic magnetic anomaly polarity sequence. Successful magnetostratigraphic correlation also depends on the presence of distinctive patterns in the polarity sequence. If the reversal rate is high or if the sequence has no special identifying characteristics, it is not possible to make an unequivocal correlation. All these problems contribute to the difficulty of interpreting the Miocene magnetostratigraphy at DSDP Hole 521A.

\section{SAMPLING AND MEASUREMENT}

Fresh sediment samples were taken at the Lamont-Doherty Geological Observatory Core Repository with the aid of a special device 
developed by Dr. N. Petersen. This device is equivalent to a miniature piston corer and gives well-oriented, small cylindrical samples (volume $3.3 \mathrm{~cm}^{3}$ ) of the soft sediment. These samples were extruded directly into close-fitting, cylindrical plastic containers that had a ridged inner surface to prevent any sample rotation and that were tightly capped to reduce dehydration. When some of the cylinders were opened several weeks later, few of the samples were found to have shrunk appreciably. About $37 \mathrm{~m}$ of core were sampled at intervals of 7 to $10 \mathrm{~cm}$ and gave 324 samples for this study.

The remanent magnetizations were measured with a three-axis cryogenic magnetometer interfaced with a Hewlett-Packard 1000 minicomputer. Each component was sampled 10 times in each measurement position; the three components were measured in each of three measurement positions. A small cubic holder was used to hold the plastic cylinder containing the sample. The reliability of each measurement was controlled by determining the angular dispersion of the repeated measurements. The above procedure gave excellent results; the dispersion was generally only a few degrees and often less than $1^{\circ}$.

\section{MAGNETIC PROPERTIES}

An indication of the magnetic mineralogy of the samples was obtained by observing the acquisition of isothermal remanent magnetization (IRM) in 33 selected samples. Dunlop (1972) has shown that this procedure reveals the complete coercivity spectrum of the sample and that this can be diagnostic of the magnetic mineral. Typical IRM acquisition in DSDP Hole 521A samples is illustrated in Figure 1. In progressively stronger fields the IRM increases sharply at first, reaching a value near to saturation IRM in fields of less than $0.2 \mathrm{~T}$. In stronger fields most samples show little significant further increase of IRM; the remanence of these samples is car-

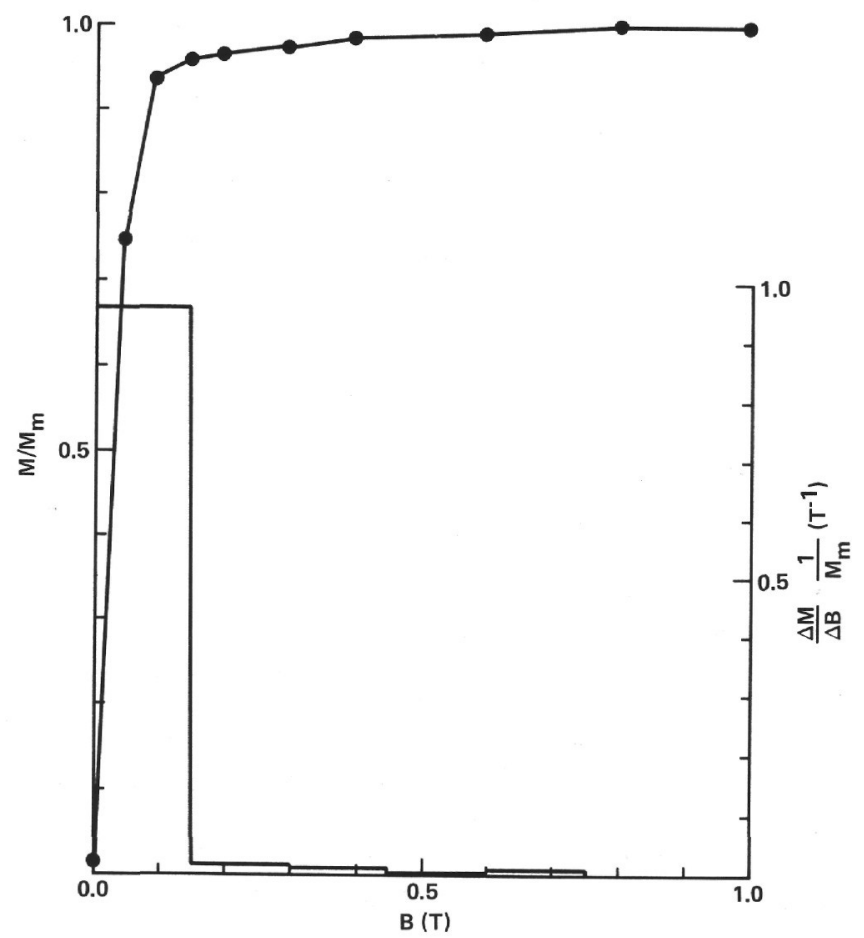

Figure 1. Acquisition of IRM $\left(\mathrm{M}_{\mathrm{m}}=\right.$ maximum value of $\mathrm{IRM}=1.93$ $\mathrm{Am}^{-1}$ ) in a typical late Miocene sediment sample from Hole $521 \mathrm{~A}$ (Sample $521 \mathrm{~A}-10-2,5 \mathrm{~cm}) .(\Delta \mathrm{M} / \Delta \mathrm{B}) / \mathrm{M}_{\mathrm{m}}$ is the coercivity spectrum of the sample; it shows that most of the ferromagnetic fraction is in the coercivity range below $0.15 \mathrm{~T}$ and probably corresponds to detrital magnetite. ried virtually exclusively by a low-coercivity magnetic mineral, probably magnetite. The IRM curves of some samples show a slight but definite increase up to about $0.8 \mathrm{~T}$; in these samples the low-coercivity (magnetite) component also dominates the coercivity spectrum, but a minor hard component is also present.

The stability of the remanence was investigated in two suites of 10 pilot samples. These samples were distributed at approximately equal intervals along the core. One suite was progressively demagnetized in alternating magnetic fields that were increased stepwise up to a maximum of $60 \mathrm{mT}$. A small unstable component was usually present at first, but it was easily removed in a peak field of 5 to $10 \mathrm{mT}$. Above this step the remanent magnetization was demagnetized in a uniform fashion. Vector plots indicate the presence of a single component that decays smoothly but does not reach the origin in peak magnetic fields of $40 \mathrm{mT}$ (Fig. 2). In stronger demagnetizing fields the remanence signal became erratic, most likely as the result of the addition of spurious components.

The second suite of samples was progressively demagnetized thermally. The samples were removed from their plastic cylinders; the marks left by the holder ridges enabled accurate re-orientation for later measurement. Before the first heating steps, the samples were wrapped in aluminum foil and dried at room temperature in nitrogen gas in the field-free space within mu-metal shields. The low-field magnetic susceptibility was measured before and after dehydration and showed no change that might be indicative of chemical alteration. The remanence often underwent major changes in intensity; the direction was affected to a lesser degree. It appeared to make no difference whether the samples were dehydrated in an inert atmosphere or in air. Thermal demagnetization of the dehydrated samples removed an unstable component below $200^{\circ} \mathrm{C}$ and defined a vector at higher temperatures that demagnetized fairly linearly toward the origin of a vector diagram (Fig. 3). The remanence in some samples demagnetized noisily at high temperature, indicating possible alteration of the magnetic mineralogy. The susceptibility was measured after each heating step. It increased gently and continuously in all samples up to $500^{\circ} \mathrm{C}$ (Fig. 4). Over this temperature range the magnetic mineralogy appeared to be fairly stable thermodynamically and exhibited no sudden increase indicative of generation of a new magnetite phase, as has been reported during the thermal treatment of pelagic limestones (Lowrie and Heller, 1982).

Thermal demagnetization was on the whole more effective in cleaning the sediment remanences than AF demagnetization. Thermal cleaning was also effective in samples that had been previously AF demagnetized (Fig. 5). Although AF cleaning usually resulted in the correct polarity, the stable final direction was often reached only after additional thermal demagnetization.

On the basis of these pilot studies the main collection was AF demagnetized in peak fields of $10,20,30$, and $40 \mathrm{mT}$. Where this treatment did not produce a satisfactory cleaned direction, the sample was further demagnetized thermally. 
A
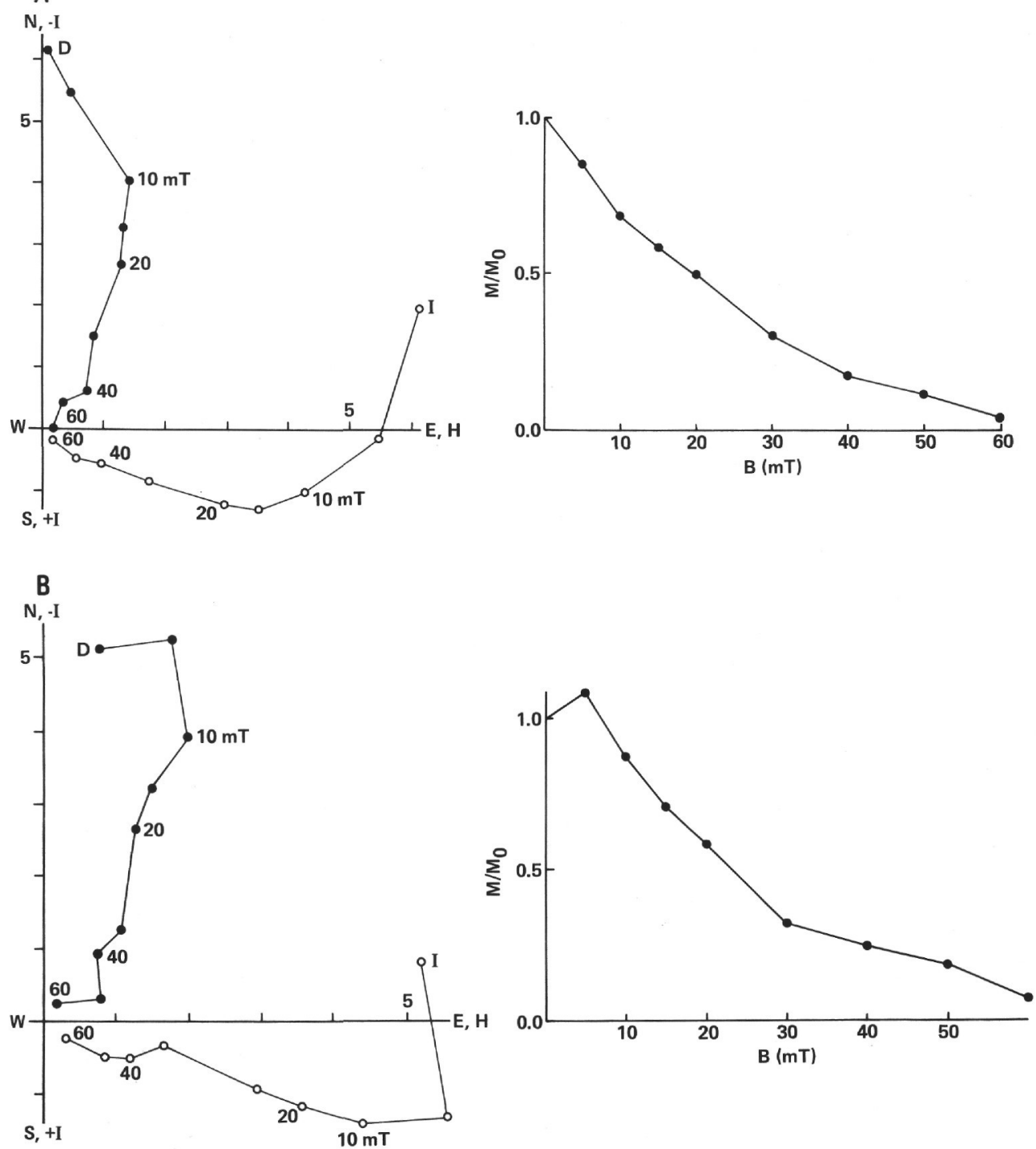

Figure 2. Results of stepwise alternating field demagnetization of pilot samples, plotted on vector diagrams. Solid points represent components in the horizontal plane; open points define the variation of the vector in the (variable) vertical plane, which also contains the horizontal vector. Numbers on the scales in the right-hand plots give the peak field, B, in millitesla (mT). Although in demagnetization fields above $10 \mathrm{mT}$ the vectors demagnetize in the general direction of the origin, they do not reach it by $60 \mathrm{mT}$, and above about $30 \mathrm{mT}$ the signal becomes noisy. This is probably due to the addition of spurious magnetization components in the AF demagnetizing process. A. Sample 521A-9-3, $32 \mathrm{~cm}$; $\mathrm{M}_{0}=6.40 \mathrm{E}-3 \mathrm{Am}^{-1}$. B. Sample 521A-9-3, $40 \mathrm{~cm} ; \mathrm{M}_{0}=5.21 \mathrm{E}-3 \mathrm{Am}^{-1}$.

\section{MAGNETIC STRATIGRAPHY}

The intensity of natural remanent magnetization (NRM) was consistent between 0.001 and $0.01 \mathrm{~A} / \mathrm{m}$ but showed several systematic fluctuations down the core (Fig. 6). The intensity variations were matched by corresponding changes in magnetic susceptibility, which indicates that the controlling factor was the core lithology (in particular, the ferromagnetic and paramagnetic mineralogies) and not the depositional field intensity. The remanent intensity shows more scatter than the susceptibility, possibly because of the presence of low-coercivity components.
The definition of the magnetic polarity stratigraphy in Hole 521A was quite variable. Below about $60 \mathrm{~m}$ subbottom the reversal stratigraphy was clearly defined, even in undemagnetized samples (Fig. 6). From 48 to $60 \mathrm{~m}$ sub-bottom, normal and reversed magnetozones were unequivocally present in stratigraphic plots of the magnetically cleaned, characteristic remanent magnetization (ChRM), but they presented a more ragged appearance. The upper part of the core (above $45 \mathrm{~m}$ subbottom) consisted largely of shallow, more scattered inclinations, and only a feeble zonation was possible on the basis of AF-demagnetized directions alone. The combination of $\mathrm{AF}$ and thermal cleaning led to a distinct 

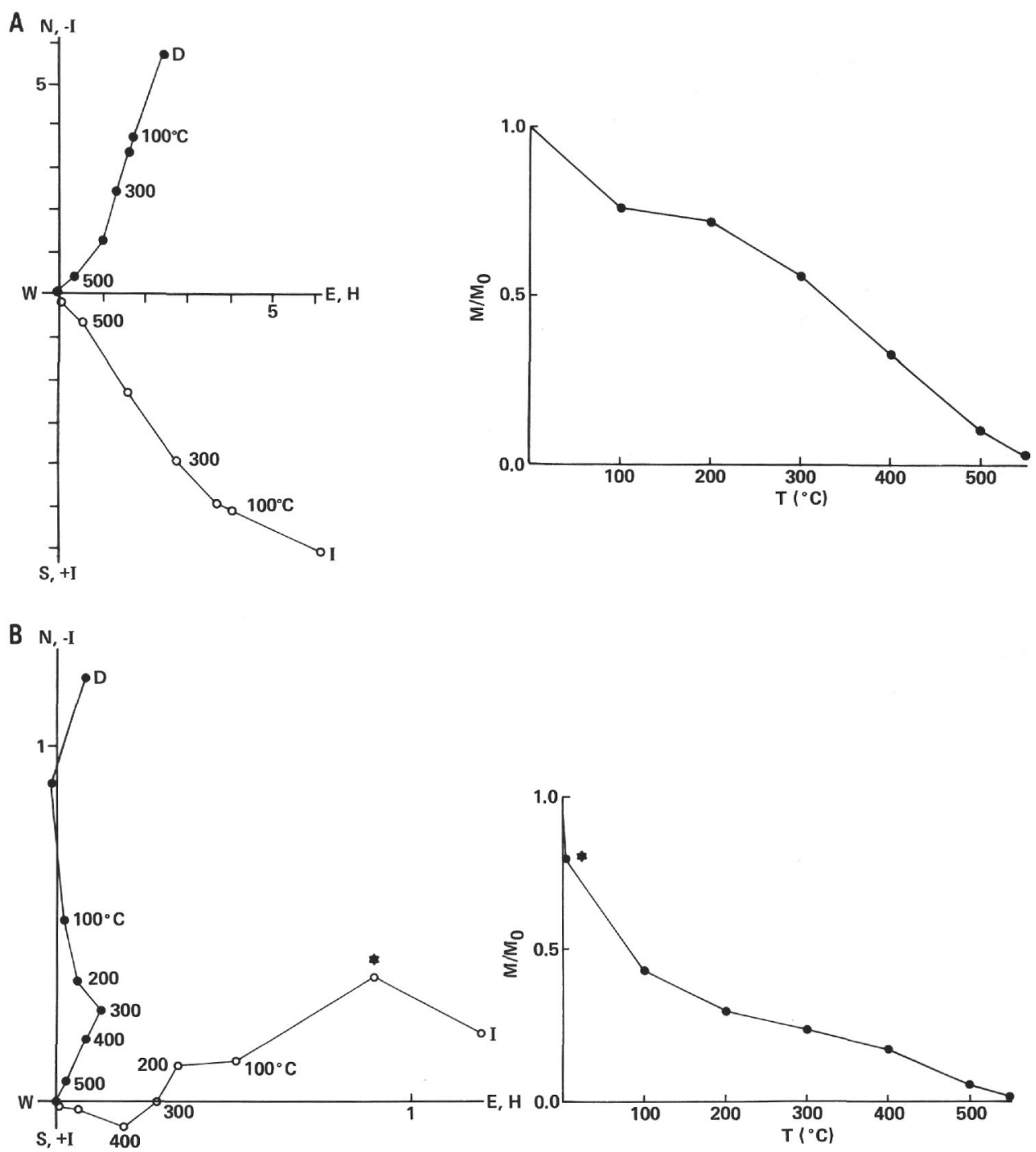

Figure 3. Results of thermal demagnetization of pilot samples. A. Sample 521A-15-3, $108 \mathrm{~cm} ; \mathrm{M}_{0}=8.57 \mathrm{E}$ $-3 \mathrm{Am}^{-1}$. B. Sample $521 \mathrm{~A}-10-2,137 \mathrm{~cm}, \mathrm{M}_{0}=1.20 \mathrm{E}-2 \mathrm{Am}^{-1}$. For plot descriptions see Fig. 2 caption; numbers on the scales in the right-hand plots indicate temperature, T. An unstable component is removed at temperatures below about $100^{\circ} \mathrm{C}$ and the stable vector to the origin is defined above temperatures of about $400^{\circ} \mathrm{C}$. The star in Fig. 3B indicates the intensity and direction of the remanence after preliminary dehydration of this sample.

improvement in the magnetic polarity zonation as determined from the ChRM inclinations (Fig. 7).

The samples were not oriented azimuthally relative to geographic coordinates. However, core continuity was often very good within individual, 1.5 -m-long core sections. Therefore, the ChRM directions were averaged (Fisher, 1953) to get the mean direction for each section; the declination of each sample in the section was then adjusted by subtracting the declination of the section mean direction. This is equivalent to setting the mean declination of each core segment to an arbitrary common value, in this case the present geographic north. The mutual consistency of the inclinations and declinations within well defined stratigraphic intervals indicates that little or no distortion had been introduced within a core section by possible twisting of the core. It also justifies this method of increasing the amount of usable magnetostratigraphic information from Hole 521A. The adjusted declinations were used in conjunction with the corresponding inclinations to compute the relative latitude of the virtual geomagnetic pole (VGP). The magnetic polarity stratigraphy was interpreted from the stratigraphic variation of VGP latitude (Fig. 7).

\section{COMPARISON WITH HOLE 521 AND OCEANIC REVERSAL SEQUENCE}

Shipboard nannofossil identifications made on corecatcher samples provide a broad biostratigraphic framework for the magnetostratigraphy. In addition, the nannofossils in the sediment from 46.8 to $54.7 \mathrm{~m}$ sub-bottom at Hole 521A were zoned by K. Perch-Nielsen (this vol.). The results confirmed the shipboard dates for this hole, except that the core-catcher sample from Core 12 was reassigned to Zone NN8; Zones NN9 and NN10 are found higher in Core 12. Comparison of the paleontological dates for Hole 521 below $60 \mathrm{~m}$ sub-bottom and 


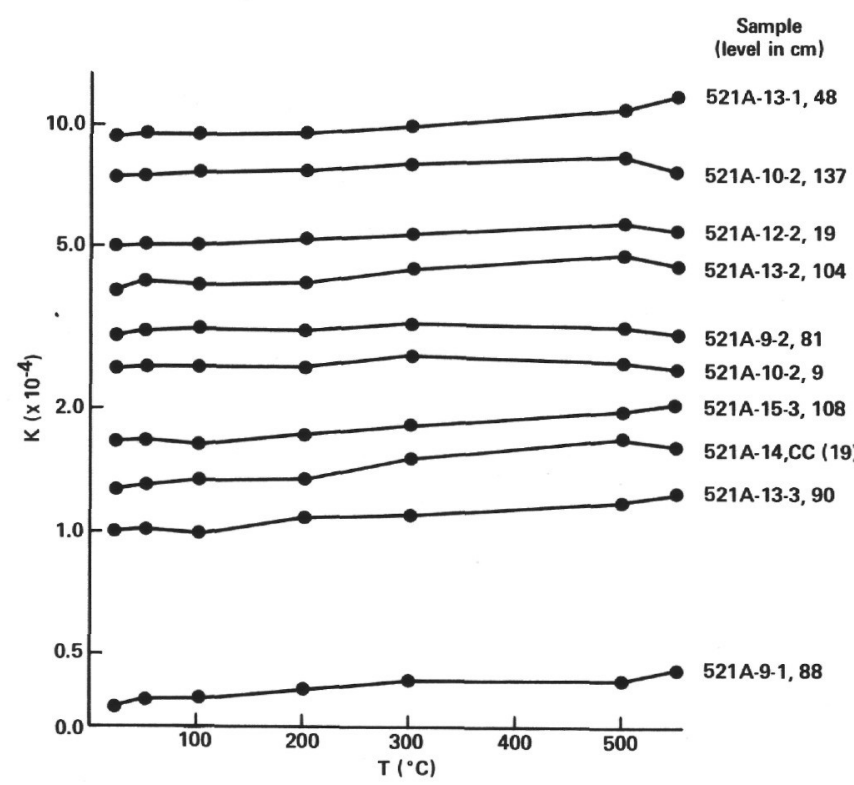

Figure 4. Variation of magnetic susceptibility (K) following different stages of incremental heating of thermally demagnetized pilot samples. Susceptibility gently increases with progressive heating, but there is no sudden change that would be indicative of a massive modification of the magnetic mineralogy within the range of heating.
Hole 521A below $45 \mathrm{~m}$ sub-bottom shows good agreement; above these levels different ages are associated with the sediments at comparable depths below the seafloor.

The magnetic polarity zonation of Hole 521A was compared with the magnetic stratigraphy obtained in shipboard studies (Tauxe et al, this vol.) for Hole 521 (Fig. 8). Although the two drilling sites are very close to each other, their magnetic stratigraphies do not agree well.

The magnetic time scale of Lowrie and Alvarez (1981) has been used to compare the Hole 521A magnetic stratigraphy with the record of magnetic field polarity interpreted from oceanic magnetic anomalies. The differences between this time scale and the Ness et al. (1980) and LaBrecque et al. (1977) time scales are very small in the Neogene. For example, they predict ages of 16.21 , 15.96 , and $15.72 \mathrm{~m} . y$. , respectively, for the younger reversal boundary of Anomaly 5C.

The clearly positive polarity of the deepest sediments at Hole $521 \mathrm{~A}$ can probably be associated with the normal polarity of the magnetic field at the time of formation of Anomaly 5C, on which this site was drilled. The basal sediments correspond in age to nannofossil zone NN4. The overlying, well-defined negative magnetozone from about $61.5 \mathrm{~m}$ to $68 \mathrm{~m}$ sub-bottom can probably be
A

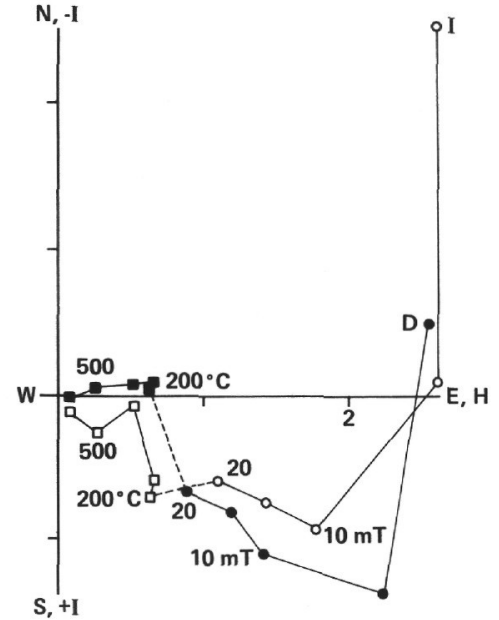

B

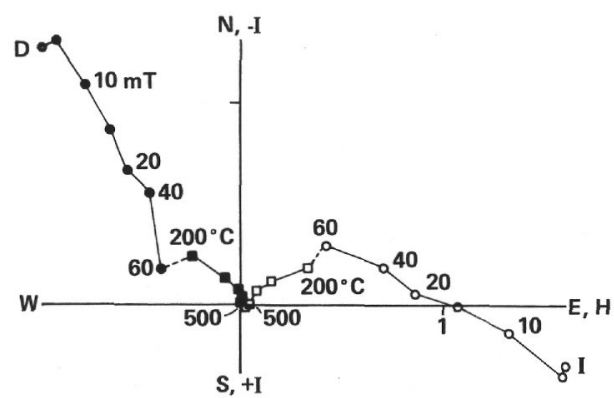

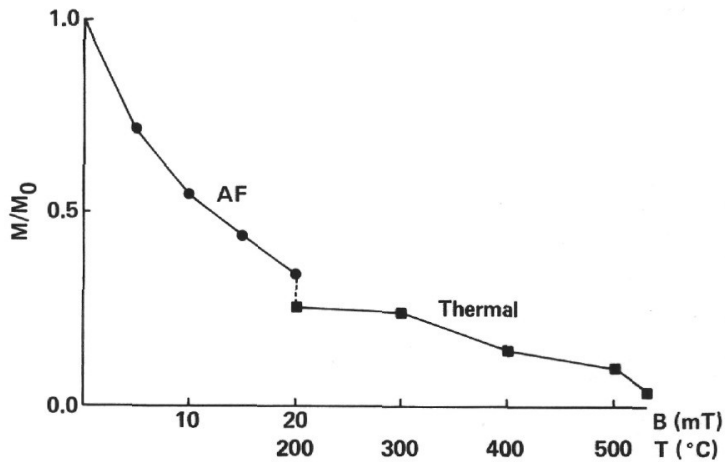

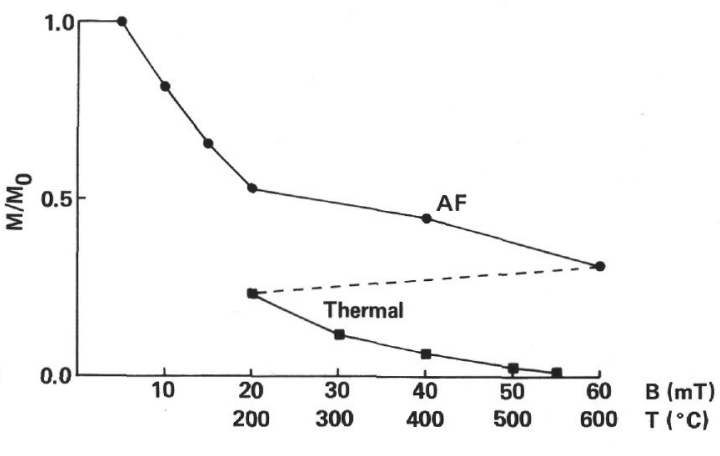

Figure 5. Examples of thermal cleaning following AF cleaning to (A) $20 \mathrm{mT}$ peak field (Sample 521 A-9-2, $49 \mathrm{~cm} ; \mathrm{M}_{0}=3.62 \mathrm{E}-3 \mathrm{Am}^{-1}$ ) and (B) $60 \mathrm{mT}$ peak field (Sample 521A-14, CC (23 cm); $\mathrm{M}_{0}=1.61 \mathrm{E}-2$ $\left.\mathrm{Am}^{-1}\right)$. Numbers in the scales in the right-hand plots identify the peak field or temperature. In most samples studied, the final thermal treatment resulted in improved magnetic cleaning. 


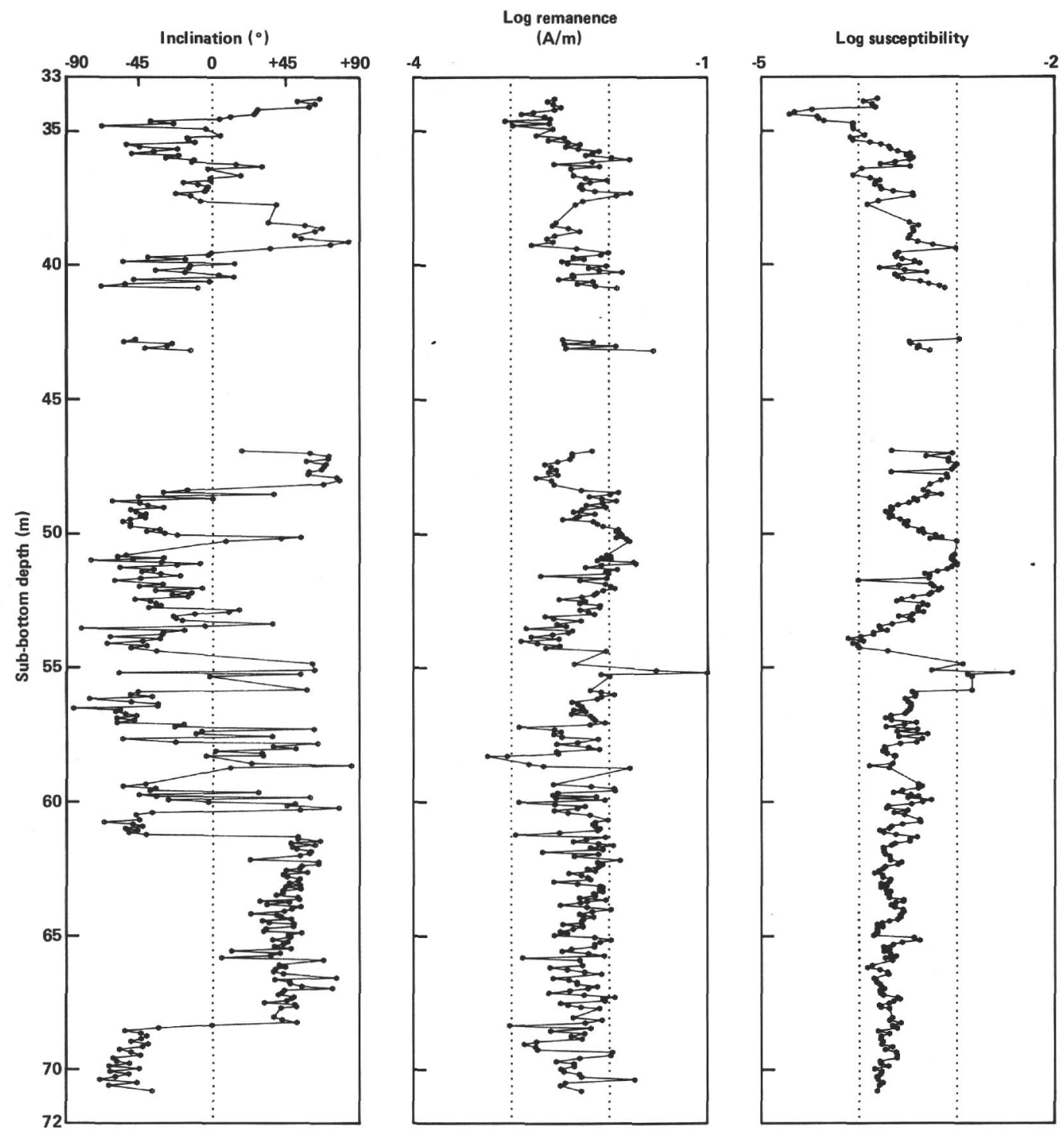

Figure 6. Stratigraphic plots of the inclination, magnetic susceptibility, and intensity of natural remanent magnetization (NRM) at Hole 521A. Number of samples: 324. A roughly defined sequence of magnetic polarity zones can be detected even though the samples are uncleaned. The similarity between the changes in magnetic susceptibility and NRM intensity shows the effects of lithologic fluctuations.

correlated to the negative polarity that followed Anomaly 5C (Fig. 8).

Short magnetozones of normal and reversed polarity occur from $51.5 \mathrm{~m}$ to $61.5 \mathrm{~m}$ sub-bottom, interspersed with apparent "polarity zones" that are unfortunately represented only by single specimens and that therefore cannot be trusted. However, a broad, well-defined normal magnetozone from $48.3 \mathrm{~m}$ to $51.4 \mathrm{~m}$ sub-bottom can probably be correlated with Anomaly 5. The nannofossils from these depths correspond to Zones NN8/ NN9, and the base of the magnetozone is associated with Zones NN6/NN7. These correlations disagree with the results of Ryan et al. (1974), who associated Anomaly 5 with the younger nannofossil zones NN10/NN11.

Only a few samples were obtained from sub-bottom depths of 41 to $47 \mathrm{~m}$ because of poor core recovery; the samples have normal polarity but are too few to help the magnetic stratigraphy. The samples from 34 to $41 \mathrm{~m}$ subbottom are dominantly of reversed magnetic polarity.

\section{DISCUSSION}

The ages associated with magnetic reversal boundaries from Anomaly 5 to Anomaly $5 \mathrm{C}$ in the magnetic time scale of Lowrie and Alvarez (1981) have been used to determine ages for the corresponding magnetozones in Hole 521A. The sedimentation rates between these tielevels have then been computed. For the interval from 48 to $61 \mathrm{~m}$ sub-bottom the effective sedimentation rate is fairly constant at around $2.0 \mathrm{~m} / \mathrm{m} . \mathrm{y}$. This is a very low rate, even for pelagic sediments. Only in the deepest part of Hole 521A, between about $61 \mathrm{~m}$ sub-bottom and the bottom of the hole at about $71 \mathrm{~m}$ sub-bottom, is the sedimentation rate appreciably higher. 

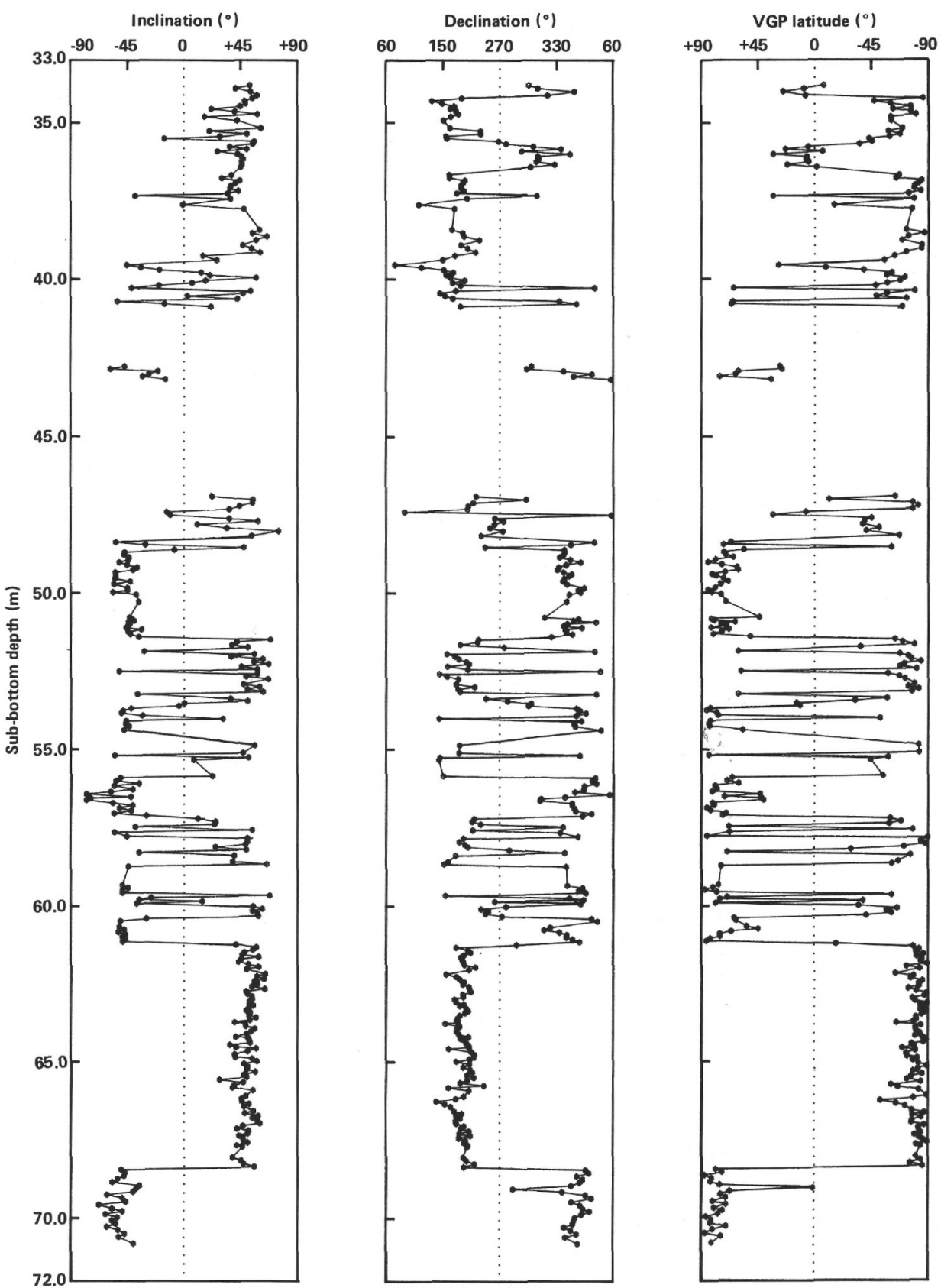

Figure 7. Stratigraphic variations of the inclination and relative declination (defined by subtracting the mean declination of each core section from individual declinations in the section) at Hole 521A. The latitude of the virtual geomagnetic pole (VGP) was then computed as a guide in developing the magnetic polarity zonation for this hole.

The combined effects of dissolution and low (and possibly variable) sedimentation rate spoil the magnetic stratigraphy in the cores and make the identification of individual polarity zones or sequences difficult. The magnetic polarity zonation of the sediments can only be correlated in a broad way to the late Miocene oceanic magnetic anomaly polarity record. The identification of the polarity zones corresponding to oceanic magnetic Anomalies 5 and $5 \mathrm{C}$ is, however, reasonable. We have tentatively associated Anomaly 5B with the magnetozones overlying the negative magnetozone younger than
Anomaly $5 \mathrm{C}$; the interpretation of Anomaly $5 \mathrm{~A}$ is more speculative (Fig. 8).

\section{REFERENCES}

Dunlop, D. J., 1972. Magnetic mineralogy of unheated and heated red sediments by coercivity spectrum analysis. Geophys. J. R. Astron. Soc., 27:37-55.

Fisher, R. A., 1953. Dispersion on a sphere. Proc. R. Soc. London Ser. $A$, 217:295-305.

LaBrecque, J. L., Kent, D. V., and Cande, S. C., 1977. Revised magnetic polarity time scale for Late Cretaceous and Cenozoic time. Geology, 5:330-335. 
Lowrie, W., and Alvarez, W., 1977. Upper Cretaceous-Paleocene magnetic stratigraphy at Gubbio, Italy. III. Upper Cretaceous magnetic stratigraphy. Geol. Soc. Am. Bull., 88:374-377.

, 1981. 100 million years of geomagnetic polarity history. Geology, 9:392-397.

Lowrie, W., Alvarez, W., Napoleone, G., Perch-Nielsen, K., Premoli Silva, I., and Toumarkine, M., 1982. Paleogene magnetic stratigraphy in Umbrian pelagic carbonate rocks: the Contessa sections, Gubbio. Geol. Soc. Am. Bull., 93:414-432.

Lowrie, W., and Heller, F., 1982. Magnetic properties of marine limestones. Rev. Geophys. Space Phys., 20:171-192.

Napoleone, G., Premoli Silva, I., Heller, F., Cheli, P., Corezzi, S., and Fischer, A. G., 1983. Eocene magnetic stratigraphy at Gubbio, Italy, and its implications for Paleogene geochronology. Geol. Soc. Am. Bull., 94:181-191.

Ness, G., Levi, S., and Couch, R., 1980. Marine magnetic anomaly timescales for the Cenozoic and Late Cretaceous: a precis, critique and synthesis. Rev. Geophys. Space Phys., 18:753-770.
Opdyke, N. D., 1972. Paleomagnetism of deep-sea cores. Rev. Geophys. Space Phys., 10:213-249.

Ryan, W. B. F., Cita, M. B., Rawson, M. D., Burckle, L. H., and Saito, T., 1974. A paleomagnetic assignment of Neogene stage boundaries and the development of isochronous datum planes between the Mediterranean, the Pacific and Indian oceans in order to investigate the response of the world ocean to the Mediterranean "salinity crisis". Riv. Ital. Paleontol. Stratigraf., 80:631-688.

Tauxe, L., and Opdyke, N .D., in press. A time framework based on magnetostratigraphy for the Siwalik sediments of the Khaur area, Northern Pakistan. Palaeogeogr. Palaeoclimatol. Palaeoecol.

Theyer, F., and Hammond, S. R., 1974. Paleomagnetic polarity sequence and radiolarian zones, Brunhes to polarity epoch 20. Earth Planet. Sci. Lett., 22:307-319.

Date of Initial Receipt: June 15, 1982

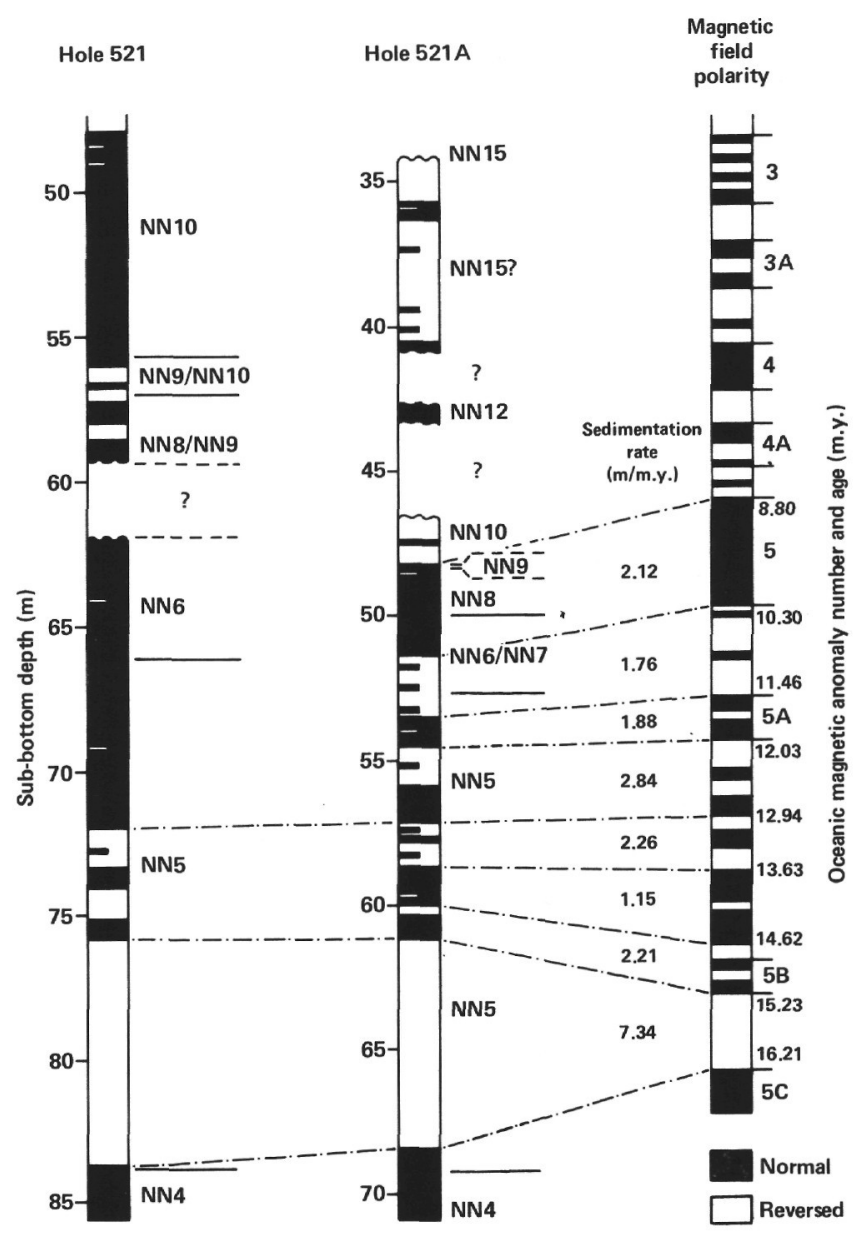

Figure 8. Comparison between the shipboard magnetic stratigraphy for Hole 521 (Tauxe et al., this vol.), the magnetic stratigraphy of Hole 521A (this study), and the late Miocene magnetic polarity time scale of Lowrie and Alvarez (1981). Nannofossil zonations are from shipboard and shore-based studies. 